\title{
Leadership Integrity and Diversity in the Workplace
}

\author{
Jack T. McCann ${ }^{1}$, Betsy H. Sparks ${ }^{2 *} \&$ Thomas F. Kohntopp ${ }^{3}$ \\ ${ }^{1}$ Tusculum College, Greeneville, TN USA \\ ${ }^{2}$ South College, Knoxville, TN USA \\ ${ }^{3}$ Walden University, USA \\ * Betsy H. Sparks, E-mail: bsparks1@southcollegetn.edu
}

Received: September 26, 2017

Accepted: October 6, 2017 Online Published: October 11, 2017

doi:10.22158/rem.v2n5p177

URL: http://dx.doi.org/10.22158/rem.v2n5p177

\begin{abstract}
Leadership integrity and diversity are significant factors in the relationship between leader and employee in the workplace. For employees to follow their leaders, they want someone that they can trust. They will not follow those whom they do not trust or who will not or cannot disclose a clear set of values, ethics and standards. This research examined 941 responses from workers in the United States who completed the Perceived Leader Integrity Scale (PLIS) developed by Craig and Gustafson (1998) and the Workplace Diversity Survey by De Meuse and Hostager (1996), along with demographic questions. This research also examined the relationship of perceived leadership integrity and workplace diversity.
\end{abstract}

\section{Keywords}

ethics, leadership, management, organizational leadership, perceived leadership integrity, integrity, ethical leadership, diversity

\section{Introduction}

Interest in ethical leadership and workplace diversity continues to expand due to the continuing vacuum of leadership in today's organizations. The fundamental underlying problem is that we do not understand enough about leadership, even though it is well-researched topic (Burns, 1978). It is important to search for the moral foundation of leadership and leadership behaviors that will enhance human potential in followers. The importance of leadership in creating and promoting ethical behavior in organizations has been well established in ethics literature. Bedit, Alpaslan and Green (2016) found that ethical leadership is related in a positive way to outcomes of followers, such as perceptions of leader fairness and ethical follower behavior.

Leaders set organizational goals and required behavior in the workplace and the accompanying systems to enhance employee outcomes. Leaders must also communicate the behaviors that they value and motivate their employees to achieve and to reward them when they meet these goals. Employees should 
count on leaders for direction when they encounter ethical dilemmas or challenges. Research tends to support the belief that employees will adhere to the ethical values held and exhibited by their leaders (Treviño \& Brown, 2004).

There is an extensive amount of literature about leadership ethics. Zhu, Treviño and Zheng (2016) found that many empirical works focused on the positive impacts of ethical leadership on attitudes of employees, such as job satisfaction and affective commitment of followers (Neubert et al., 2009), along with job behaviors similar to individual and group organizational citizenship behavior (Avey et al., 2012; Mayer et al., 2009), employee voice behavior (Zhu et al., 2015), job performance (Zhu et al., 2015), follower misconduct (Mayer et al., 2010), and follower deviance (van Gils et al., 2015). However, limited research has addressed whether ethical leadership is associated with workplace diversity.

This research utilized the definition of ethical leadership defined by the writings of James McGregor Burns and Bernard Bass in their works on transformational leadership (Bass, 1985; Burns, 1978). The leader's vision is one that aims to achieve moral good along with core values of integrity, trust, and morality. Those who are ethical leaders inspire others to behave in ethical ways, and they encourage and reward changes toward moral goals. The definition diversity in the workplace diversity for this research comes from Nkomo (1996), which presents a broad definition that examines the ways that members of work teams differ including race, gender, age, ethnicity and other demographic categories, including individual differences and their own. Modern definitions of workforce diversity consider how people differ and the impacts this has on a task or relationship within an organization. This definition emphasizes culture, including religion, education, sexual orientation, and additional areas that encourage support diversity which consider values, abilities, organizational function, tenure and personality.

The purpose of this research was to reduce this gap in the literature and to examine leadership behavior and workplace diversity as perceived in the United States. This research examined the following questions:

1) What are the levels of ethical leadership as perceived by respondents based on the Perceived Leader Integrity Scale (PLIS)?

2) What are the levels of workplace diversity as perceived by respondents based on the Workplace Diversity Scale (WDS)?

3) What is the relationship between ethical leadership and workplace diversity perceptions?

\section{Method}

\subsection{Theoretical Framework}

There is a great deal of research about social learning theory (Bandura, 1977) along with social exchange theory (Blau, 1964) to explain positive impacts of perceptions of followers about ethical leadership impacts on organizational outcomes. For this research, the authors considered findings of 
April, Peters, Locke and Mlambo (2010), describing four categories that exist within today's ethics literature. The first category includes leadership literature; the second category is business ethics in literature, the third category that examines the continuum of virtue ethics on and of situational social psychology. In this research, we focus primarily on leadership, the first category which and is based on leadership literature. Research also included perceived leadership integrity and diversity as behaviors from employee perspectives.

\subsection{Literature Review}

\subsubsection{Leadership Integrity}

Integrity was first proposed as an integral component in transformational leadership by Burns (1978) in Leadership and various studies have supported the links between transformational leadership and positive organizational outcomes (Lowe \& Gardner, 2000; Kroeck \& Sivasubramanium, 1996; Avolio \& Bass, 1991; Bass, Lowe, \& Bass, 1985). Bums (1978) discovered that transformational leadership emphasizes followers' needs, values, and morals. Thus, the transformational leader must recognize and incorporate the wants, needs, demands, and unmet expectations of their followers. Transformational leadership includes the entire person in a process that is mutually stimulating and elevating to both followers and leaders. The transformational leader also seeks to satisfy the higher needs of the followers in as described in Maslow's (1954) needs hierarchy. The transformational leadership theory is important for evaluating leadership honesty and effective leadership in today's organizations (Sarros \& Santora, 2001).

Brenkert (2010) discovered ethics in leadership and business is of top importance for most business executives and that it is equally represented in the literature for creating and promoting ethical behavior in organizations. There is also a growing belief that good ethics means good business and that strong leadership exists it is grounded in an ethical culture emerge (Benrjea, 2010).

According to Moorman, Darnold, Priesemuth and Dunn (2012), the definition and measurement of leadership integrity in today's business literature generally follows two basic approaches. The first approach is integrity as consistency with integrity defined by the belief that values are applied consistently. Kouzes and Posner (2002) contributed to the idea and indicated those with integrity generally practice what they preach and will do what they say they will. The second approach is where moral values form the basis of integrity. Leaders with perceived integrity are then evaluated on the values they believe it and not just on their behavior using these values.

Mayer, Davis and Schoorman (1995) presented a comprehensive view of leader integrity that includes both integrity approaches. Mayer et al. (1995) proposed that integrity is based upon moral values, as perceived by their follower, defining integrity as the follower's perception that leaders follows a set of principles in which followers agree. A leader's past behaviors, along with communication about the follower from others, that include belief that the leader has a strong sense of justice, and level of alignment with a group's along with their words, all of which have an impact the degree to which the leader is judged to have integrity. This appears to imply that the more comprehensive view is integrity 
as consistency and integrity as moral value. Monga (2016) found an additional meaning of integrity is consistency in the face of adversity. McFall (1987) proposed that true integrity may be constant even when faced with adverse circumstances. Considering this definition, a person of integrity holds moral steadfastness and is not tempted even when considering great personal cost. This may be a component of integrity, but does not completely define integrity. Courage is also associated with morally perceived behavior in those situations of adversity and challenge (Palanski et al., 2015).

\subsubsection{Workplace Diversity}

Organizations consider the concept of diversity differently from other business paradigms shaping the philosophy on diversity (Rawat \& Basergekar, 2016). Moral paradigm purports that discrimination is wrong, illegal, and immoral while social paradigm implies that solutions to diversity for a country or region must be different. The competitive advantage paradigm indicates that there is a competitive rationale founded on diversity and inclusion policy. Hunt, Layton and Prince (2015) found that companies known for positive diversity in areas of sex, racial, and ethnicity are more apt to earn positive financial returns closer to national average for their industry. Companies that do not practice diversity in these areas are statistically less likely to achieve above these types of financial returns. Therefore, diversity may be considered a competitive advantage.

To overcome challenges to achieve diversity and enjoy its rewards, top managers have recognized the need to adopt effective diversity management practices (Rawat \& Basergekar, 2016). Organization's perspective towards diversity may govern the ability of its employees to communicate effectively and reap sustained benefits from diversity (Lambert, 2016). Ely and Thomas (2001), discovered three views about cultural diversity that may improve or harm work group functioning. One view is the fairness-and-discrimination perspective, which is how organizations comply with the law, but do not necessarily benefit from workplace diversity. Access-and-legitimacy perspective is the way in which racial minorities benefit through workforce access, however, the organization may not receive benefit from these activities. Integration-and-learning perspective is where organizations and employees benefit from a diverse workforce. According to Rawat and Basergekar (2016), found that these perspectives influence the organizational culture of an organization. However, the connection between these perspectives in terms of diversity and innovation has not been determined.

Richard (2000) found that culturally diverse organizations possess valuable resources that are hard to imitated and impact market performance, return on equity, and productivity. In a positive way Top management team diversity is also linked to firm performance as female representation brings informational and social diversity benefits (Dezso \& Ross, 2012). Badal (2011) postulated that increased performance can be attributed to better problem-solving methods, dissimilar viewpoints and ideas, market insights, thought, behaviors, skills, and knowledge which may spark innovation. Procedural justice is an important part of the recipe to help increase diversity and inclusivity within an organization. Diversity and engagement provide positive effects on the bottom line by improving financial performance (Badal, 2014). Gender diverse organizations realized 14\% higher revenues than 
their non-gender diverse peers, resulting in retail benefits of $46 \%$ higher revenue (Badal, 2014). Diversity and engagement may impact increased revenue and performance which include reduced risk and legal liability, attraction and retention of the best human resources talent, broader organization customer base, and improved advertising and marketing (Badal, 2014).

\subsection{Methodology}

This research examined levels of ethical leadership of supervisors as perceived by employees using the Perceived Leader Integrity Scale (PLIS). In addition, the levels of perceived attitudes of workplace diversity using the Workplace Diversity Survey (WDS) were measured. The research also considered whether there was a relationship between leader integrity and workplace diversity.

\subsubsection{Measures}

Craig and Gustafson's Perceived Leader Integrity Scale was utilized in this study to measure the perceived ethical integrity of respondents about their leader's behaviors in this population. The PLIS evaluates a leader's ethics by examining the degree to which subordinates perceive leaders behaving in a manner that benefits the greatest number of people possible (Craig \& Gustafson, 1998).

The PLIS is made up of 31 statements utilizing a 5-point Likert scale, Responses range from 1 to $5(1=$ Not at all; 2 = Once in a while; $3=$ Sometimes: $4=$ Fairly often; $5=$ Frequently, if not often). PLIS statements are presented, in the following way, "Would use my mistakes to attack me personally" and "Always gets even". Statements are developed so that lower scores present higher levels of leader integrity perceptions. These 31 statements are separated into three score ranges that represent the 5-point Likert scale.

High ethical (score range from 31-71);

Moderate (score range from 72-113);

Low ethical (score range from 114-155).

High ethical score range shows that subordinates perceive their supervisor behaviors as highly ethical, trustworthy, and principled. The score range moderate shows that perceptions of subordinates are viewed as moderately ethical and that they occasionally engage in unethical behavior. The lower ethical score range indicates the perceptions of employees about their supervisors is unethical, dishonest, unfair, and even unprincipled.

Workplace diversity was measured by the WDS, developed by De Meuse and Hostager (1996). This instrument captures meaningful differences on diversity perceptions and attitudes, dividing the distribution of summary score into the three categories. Respondents in the upper third ( +35 to +11$)$ are classified as optimists. Respondents in the middle third ( +10 to -10$)$ are classified as realists. Individuals in the lower one-third (-11 to -35$)$ are classified as pessimists.

The WDS requires participants to respond explicitly to all the items presented. Among other things, this means that the format of the WDS requires participants to respond to an equal number of positive and negative items on each of the five dimensions of emotional reactions, judgments, behavioral intentions, personal consequences, and organizational outcomes. The WDS presents complete sentences including 
key words representing the dimensions. By presenting the words in complete sentences, the WDS exposed participants to a fully specified stimulus, which, in turn, placed more limits on the range of possible meanings that subjects could have assigned to each word. Participants reported the extent of their agreement with each statement on the WDS by using a 5-point Likert scale.

\subsubsection{Population}

The population for this study included employees in the United States who were employed full or part-time. Employees for this population could have had any level of education from not completing high school to graduate degrees and employed in healthcare, non-profit, technology, energy and utilities, transportation, materials, consumer services, financial services, education, government, professional services and manufacturing. All job levels from entry level to owner/executive level comprised the population for this study.

\subsubsection{Procedure}

To elicit a greater sample size and enhance the estimation of our model, the survey was distributed to full-time and part-time employees in the United States through Survey Monkey (www.surveymonkey.com). The criterion for inclusion was that the individual taking the survey must have been employed in a full-time or part-time capacity in an organization. Survey Monkey panels are indicative of the population, as Survey Monkey uses regular benchmarking surveys. No other criteria for inclusion were included except for being employed as indicated above. Each Survey Monkey panel member was offered a small non-cash award for completion (i.e., charitable donations or sweepstakes entries). The survey remained open for approximately five weeks before it was closed. Upon closure, the data file for the survey was downloaded from Survey Monkey and analyzed using IBM SPSS version 24 and IBM AMOS version 24. A Harmon's single factor was used to test for common method bias. A single factor did not emerge that explained more than $40 \%$ of the variance, indicating that common method bias was not a cause for concern (Podsakoff et al., 2003).

The reliability of the PLIS instrument was assessed using Cronbach's alpha, which exceeded the recommended .70 . The reliability of the WDS instrument was assessed for the five diversity dimensions using Cronbach's alpha values. To assess the dimensions, all negative scale items were recoded. Each dimension of the WDS instrument exhibited a Cronbach's alpha greater than .70, except for personal consequences, which exhibited a .61. Individual items in the WDS instrument were examined. It was decided to retain personal consequence items based on original survey validation by Craig and Gustafson (1998).

\section{Result}

Over 1,084 individuals meeting the employment criteria opened the survey, which resulted in 941 useable responses. The overall abandonment rate was $13.2 \%$ with a survey span of approximately 5 weeks. Incomplete responses with more than $5.0 \%$ missing values and responses exhibiting straight lining were eliminated. Table 1 shows the demographics of our sample with PLIS and WDS score 
information listed for each group. This survey also addressed five different demographic areas for employment status, gender, industry, job level, and education level. Choices for respondent sex options were male or female. All other options for demographics were dropdown menus with the options listed as shown in Table 1. The mean PLIS score for every demographic category was in the "highly ethical" range (31-72) as shown in Table 1. However, the standard deviations were large. More full-time employees responded to the survey, as did more males and technology workers. Intermediate job levels and employees with bachelor degrees were also more highly represented. The mean PLIS score for males was significantly greater than for females $(t=3.81, p<.01)$. Higher scores on the PLIS indicated males perceived their leaders as having less integrity than females perceived their leaders. The mean WDS score was significantly greater for females than for males $(t=-5.58, p<.01)$, indicating that females are more optimistic about diversity in the workplace compared to males. There were no significant differences in full-time and part-time employees on the PLIS $(\mathrm{t}=-.28, p=.77)$ and WDS scores $(t=-1.08, p=.28)$.

Table 1. Demographics

\begin{tabular}{|c|c|c|c|c|c|c|}
\hline & $\mathrm{N}$ & $\%$ & PLIS M & PLIS SD & WDS M & WDS SD \\
\hline \multicolumn{7}{|l|}{ Employment Status } \\
\hline Full-time & 751 & 79.81 & 59.97 & 26.07 & 13.01 & 15.85 \\
\hline Part-time & 190 & 20.19 & 60.57 & 26.12 & 14.43 & 17.37 \\
\hline \multicolumn{7}{|l|}{ Gender of Employee } \\
\hline Male & 557 & 59.19 & 62.76 & 26.01 & 10.89 & 16.21 \\
\hline Female & 384 & 40.81 & 56.22 & 25.70 & 16.79 & 15.49 \\
\hline \multicolumn{7}{|l|}{ Industry of Employment } \\
\hline Health care & 96 & 10.20 & 52.79 & 25.25 & 17.94 & 15.98 \\
\hline Non-profit & 45 & 4.78 & 56.56 & 24.72 & 18.16 & 16.21 \\
\hline Technology & 229 & 24.34 & 62.45 & 23.89 & 9.77 & 15.06 \\
\hline Energy and Utilities & 16 & 1.70 & 61.56 & 23.26 & 12.06 & 19.25 \\
\hline Transportation & 26 & 2.76 & 69.00 & 26.52 & 8.04 & 15.70 \\
\hline Materials & 19 & 2.02 & 62.84 & 26.75 & 4.89 & 13.26 \\
\hline Consumer & 96 & 10.20 & 56.86 & 26.39 & 15.15 & 17.68 \\
\hline Finance & 81 & 8.61 & 69.47 & 30.48 & 7.98 & 15.37 \\
\hline Education & 117 & 12.43 & 58.45 & 26.36 & 17.36 & 15.98 \\
\hline Government & 53 & 5.63 & 62.09 & 26.71 & 17.51 & 15.66 \\
\hline Professional Services & 98 & 10.41 & 57.55 & 26.96 & 14.78 & 15.37 \\
\hline Manufacturing & 65 & 6.91 & 58.48 & 23.50 & 11.31 & 15.56 \\
\hline Employee's Current Job Level & & & & & & \\
\hline
\end{tabular}




\begin{tabular}{lcccccc}
\hline Executive & 25 & 2.66 & 64.68 & 28.62 & 7.44 & 15.25 \\
Senior Management & 65 & 6.91 & 63.02 & 27.20 & 11.26 & 14.17 \\
Middle Management & 268 & 28.48 & 64.32 & 25.19 & 10.97 & 15.04 \\
Intermediate & 379 & 40.27 & 58.71 & 25.90 & 14.30 & 16.64 \\
Entry & 188 & 19.98 & 56.05 & 26.45 & 16.27 & 17.02 \\
Other & 16 & 1.70 & 50.50 & 21.46 & 11.19 & 15.40 \\
Employee's Education Level & & & & & & \\
Less than high school degree & 7 & .74 & 61.71 & 22.47 & 5.86 & 11.08 \\
High school degree or GED & 56 & 5.95 & 59.16 & 26.91 & 12.13 & 17.09 \\
Some college, but no degree & 127 & 13.49 & 57.82 & 25.63 & 16.12 & 18.11 \\
Associate degree & 70 & 7.44 & 65.03 & 32.79 & 13.43 & 18.07 \\
Bachelor degree & 438 & 46.55 & 59.44 & 24.74 & 12.11 & 15.63 \\
Graduate degree & 243 & 25.82 & 61.20 & 26.39 & 14.41 & 15.22 \\
\hline
\end{tabular}

Table 2 shows the PLIS score ranges, mean, standard deviation, and frequency by perceived leader integrity level. Over $68 \%$ of the sample indicated that their leaders were "highly ethical"; while over $28 \%$ of the sample indicated, their leaders were "moderate ethical".

Table 2. PLIS Scores

\begin{tabular}{lllll}
\hline & Score ranges & $M$ & $S D$ & $\%$ \\
\hline Highly ethical & $31-71$ & 44.75 & 12.19 & 68.23 \\
Moderate ethical & $72-113$ & 89.13 & 9.87 & 28.48 \\
Low ethical & $114-155$ & 126.74 & 9.57 & 3.29
\end{tabular}

Source: Adapted from a version of the PLIS that appeared in Leadership Quarterly, 9(2), S. B. Craig and S. B. Gustafson, "Perceived Leader Integrity Scale: An Instrument for Assessing Employee Perceptions of Leader Integrity”, pp. 143-144, 1998. Used with permission of the authors.

Table 3 shows the levels of the employees' perceptions of workplace diversity and score ranges. For example, an "optimistic" score indicated that the employee indicated that they felt diversity was fair, felt little if any frustration with diversity, felt diversity promoted harmony, and highly supported diversity efforts in organizations. Those employees in the "pessimist" category might feel that diversity is worthless, withdraw from organizational diversity effort, feel frustrated, and unsupportive of diversity in the organization. Over 53\% indicated that they were "optimistic" about diversity, while $41 \%$ indicated they were in the "realist" category of diversity. 
Table 3. WDS Scores

\begin{tabular}{lcccc}
\hline & Score ranges & $M$ & $S D$ & $\%$ \\
\hline Optimistic & 11 to 35 & 25.99 & 8.57 & 53.88 \\
Realist & -10 to 10 & 0.87 & 4.67 & 41.02 \\
Pessimist & -35 to -11 & -20.81 & 8.05 & 5.10 \\
\hline
\end{tabular}

After testing for the reliability of the instrument, the correlational analysis for relationship between level of perceived leadership integrity and feelings regarding workplace diversity was calculated using the Kendall's tau. According to Kendall (1938), the Kendall tau coefficient is suitable for comparing two different ranks of data taken from the same set of individuals and tends to resemble normality for large sample sizes. The Kendall tau coefficient for correlation is also suitable for nonparametric distributions. Table 4 shows the correlations for the level of perceived leader integrity and level of workplace diversity score. There was a significant negative correlation for leaders perceived as "high ethical" on the PLIS and an optimistic employee attitude toward diversity $(n=422)$. There was a stronger negative significant correlation for leaders perceived as "high ethical" on the PLIS and a pessimist attitude toward diversity $(n=32)$. However, only 48 of the $941(5.10 \%)$ participants fell into the pessimist level for attitude toward diversity. This correlation is shown as negative due to the nature of the PLIS score, as high scores on the PLIS indicate lower ethical perception of the leader.

Table 4. Kendall's Correlations for Perceived Leader Integrity and Diversity

\begin{tabular}{lcccccc}
\hline & \multicolumn{5}{c}{ Attitude toward Diversity } \\
\cline { 2 - 7 } Perceived Leader Integrity & \multicolumn{2}{c}{ Optimistic } & \multicolumn{2}{c}{ Realist } & \multicolumn{2}{c}{ Pessimist } \\
\hline & $\tau$ & $\mathrm{N}$ & $\tau$ & $\mathrm{N}$ & $\tau$ & $\mathrm{N}$ \\
\cline { 2 - 7 } High Ethical & $-.10^{* *}$ & 422 & -.02 & 188 & $-.26^{*}$ & 32 \\
Moderate Ethical & .00 & 70 & -.04 & 185 & .08 & 13 \\
Low & -.12 & 15 & .03 & 13 & -.99 & 3 \\
\hline
\end{tabular}

$* p<.05, * * p<.01$.

Table 5 shows the Kendall's tau correlations for perceived leader integrity and the five diversity dimensions. For leaders perceived as "high ethical", there was a statistically significant $(p<.01)$ correlation with each of the five dimensions of attitude toward diversity. This indicated that participants who perceived their leaders as "high ethical" had positive attitudes in the five dimensions 
for diversity, although this is a weak relationship. For leaders perceived as "moderate ethical" and "low ethical", there were no significant associations with the five dimensions of diversity.

Table 5. Kendall's Correlations for Perceive Leader Integrity and Diversity Dimensions

\begin{tabular}{|c|c|c|c|c|c|c|}
\hline \multirow{4}{*}{$\begin{array}{l}\text { Perceived Leader } \\
\text { Integrity }\end{array}$} & & \multicolumn{5}{|c|}{ Attitude toward Diversity } \\
\hline & & Emotional & Judgments & Behavioral & Personal & Organizational \\
\hline & & Reactions & & Reactions & Consequences & Outcomes \\
\hline & $n$ & $\tau$ & $\tau$ & $\tau$ & $\tau$ & $\tau$ \\
\hline High Ethical & 642 & $-.16^{* *}$ & $-.16^{* *}$ & $-.12 * *$ & $-.17 * *$ & $-.15^{* *}$ \\
\hline Moderate Ethical & 268 & .00 & -.05 & -.08 & -.06 & .01 \\
\hline Low & 31 & -.17 & -.12 & -.12 & -.13 & -.06 \\
\hline
\end{tabular}

** $p<.01$.

\section{Discussion}

This research investigated perceived leadership integrity and workplace diversity behaviors of leaders in the United States, using the PLIS and WDS. Craig and Gustafson (1998) demonstrated that the PLIS could be used to determine subordinate perceived integrity of target leaders in organizations. The WDS provided the researchers with employee attitudes and perceptions of observed workplace diversity behaviors.

The PLIS consists only of items that assess a leader's practice of specific leader behaviors that the authors deem as unethical. Of concern is that the PLIS may not represent a complete definition of integrity because it includes no items that directly address word/deed consistency. Much like the authors' concern that definitions and measures that focus only on consistency may be limited, definitions and measures that focus only on moral behaviors may be limited then the question becomes, what is the difference between someone who is moral and someone who has integrity? In the eyes of followers, if being moral and having integrity are the same, are attributions of integrity redundant? A more comprehensive treatment of leader integrity that strives to include both integrity approaches may need to be undertaken.

The results of this research have implications for the various industries represented and the workplace in total. Research was conducted only in the United States and in additional may not represent each industry category in an equitable way. Furthermore, we did not collect the company size for the participant's place of employment. Many larger companies have diversity strategies and corporate codes of conduct in place that impacts the results of this study. Smaller companies may not have diversity strategies and goals, which may result in less focus on diversity. Therefore, results may not generalizable to all industry categories. Ethical and workplace diversity in organizations are important 
concepts and critical to the success of today's organizations and their leaders. The results of this study indicate that employees in this sample their leaders were "highly ethical". A significant relationship existed between leaders perceived as "high ethical" by their employees and an "optimistic" attitude toward diversity.

This research provides contributions to leadership and diversity literature in several ways. It provides data from the sample of full and part-time employees perceptions representing a variety of industries about leadership integrity, attitudes, and diversity within their organization. It also adds to the existing empirical data about perceived leadership integrity. In addition, this research contributes to the literature in the field of perceived sustainable leadership with data gathered from U.S. workers. This research contributes in an additional way by empirically examining ethical leadership and workplace diversity perceptions by examining correlations among the survey results and instruments used. Lastly, this research provides a database for the authors to conduct additional research about leadership ethics and diversity.

Leadership integrity and efforts toward diversity appear to be practical and important to business decision-making and relationships with stakeholders. Surie and Ashley (2008) indicate that entrepreneurial leadership is pragmatic and aimed on solving practical problems and creating value for the organization. Additional research should investigate the relationship between the PLIS and WDS as related to other organizational outcomes. Leadership in today's organizations is increasingly faced with pressure from the public to focus on diversity while also maintaining productivity and profitability. If leaders lack integrity and diversity leadership behaviors, they may not be able to achieve the strategic goals of the organization and may place their organizations in performance challenging situations (Baker \& Craig, 2006).

Ethical behavior considers not just what should be, but with what should not be and implies that ethical behavior means going beyond the requirements of the law and what may be profitable for the organization. Utilizing the PLIS to investigate long-term organizational results may yield significant findings. Furthermore, using the PLIS in additional research may provide data to assist organization in reducing conflicts about leadership and organization values. It also recommended that organizations use PLIS and WDS as a method of organization self-reflection. In addition, Drucker (2001) found that employee's own values must be compatible with the organizations to be effective. Values of leaders and employees may not necessarily be perfect, but they need to coexist. If a good level of compatibility is lacking, employees may feel disconnected and not produce positive results. Further research is also needed to find out what factors lead to high ethical diversity leadership behaviors that organizations may adopt as best practices for organizational for success.

Future research may also benefit from the comparison of supervisor self-report and employee perceptions about leadership integrity and diversity behavior in the workplace. Furthermore, determining and industry formulae for success in terms of leadership integrity and workplace diversity based on employee perceptions of their supervisors deserves additional investigation. Further research 
may need to include a qualitative component that may yield greater depth of understanding about ethical and workplace diversity perceptions and behaviors of leadership in organizations. Further research should also investigate the correlation between leadership styles, PLIS and WDS, in other industries or categories of workers.

The question of what behaviors of leadership integrity and diversity constitutes a good leader is foundational to this study. When organizations understand, and use ethical and diversity leadership tools it will help to improve performance and respond to the changes in resources, technologies, marketing methods, and distribution systems because of the continual globalization of business. According to Parry and Thomson (2002), the full integration of ethical standards including diversity leadership into an organization is not only preferred, but also necessary for long-term organizational survival.

\section{References}

April, K., Peters, K., Locke, K., \& Mlambo, C. (2010). Ethics and leadership: Enablers and stumbling blocks. Journal of Public Affairs, 10, 152-172. https://doi.org/10.1002/pa.360

Avey, J. B., Wernsing, T. S., \& Palanski, M. E. (2012). Exploring the process of ethical leadership: The mediating role of employee voice and psychological ownership. Journal of Business Ethics, 107(1), 21-34. https://doi.org/10.1007/s10551-012-1298-2

Avolio, B. J., \& Bass, B. M. (1991). The full range leadership development programs: Basic and advanced manuals. Bass, Avolio \& Associates, Binghamton New York, NY.

Badal, S. B. (2014, January). The business benefits of gender diversity. Gallup Business Journal. Retrieved from http://www.gallup.com/businessjournal/166220/business-Benefitsdiversity.aspx?g_source=diversi ty\&g_medium=search\&g_campaign=tiles

Bandura, A. (1977). Social learning theory. Prentice-Hall, Englewood, NJ.

Banerjea, P. K. (2010). Wholesome ethical leadership. IUP Journal of Corporate Governance, 9(1/2), 7-14.

Bass, B. M. (1985). Leadership and performance beyond expectations. Free Press, New York, NY.

Bedit, A., Alpaslan, C., \& Green, S. (2016). A meta-analytic review of ethical leadership outcomes and $\begin{array}{llll}\text { moderators. Journal of Business } & \text { Ethics, 139(3), 517-536. }\end{array}$ https://doi.org/10.1007/s10551-015-2625-1

Blau, P. (1964). Exchange and power in social life. Wiley, New York, NY.

Brenkert, G. C. (2010). The limits and prospects of business ethics. Business Ethics Quarterly, 20(4), 703-704. https://doi.org/10.5840/beq201020444

Burns, J. M. (1978). Leadership. Harper \& Row, New York, NY. 
Craig, S. B., \& Gustafson, S. B. (1998). Perceived leader integrity scale: An instrument for assessing employee perceptions of leader integrity. Leadership Quarterly, 9(2), 127-145. https://doi.org/10.1016/S1048-9843(98)90001-7

De Meuse, K., \& Hostager, T. (2001). Developing an instrument for measuring attitudes toward and perceptions of workplace diversity: An initial report. Human Resources Development Quarterly, 12(1), 33-51. https://doi.org/10.1002/1532-1096(200101/02)12:1<33::AID-HRDQ4>3.0.CO;2-P

Dezso, C. L., \& Ross, D. G. (2012). Does female representation in top management improve firm performance? A panel data investigation. Strategic Management Journal, 33(9), 1072-1089. https://doi.org/10.1002/smj.1955

Drucker, P. F. (2001). The essential Drucker: The best of sixty years of Peter Drucker's essential writings on management. Harper Collins Publishers, Inc., New York, NY.

Ely, R. J., \& Thomas, D. A. (2001). Cultural diversity at work: The effects of diversity perspectives on work group processes and outcomes. Administrative Science Quarterly, 46, 229-273. https://doi.org/10.2307/2667087

Hunt, V., Layton, D., \& Prince, S. (2015, January). Why diversity matters. Retrieved from http://www.mckinsey.com/business-functions/organization/our-insights/why-diversity-matters

Kendall, M. (1938). A new measure of rank correlation. Biometrika, 30(1/2), 81-93. https://doi.org/10.1093/biomet/30.1-2.81

Kouzes, J. M., \& Posner, B. Z. (2007). The leadership challenge (4th ed.). Jossey-Bass, San Francisco, CA.

Lambert, J. (2016). Cultural diversity as a mechanism for innovation: Workplace diversity and the absorptive capacity framework. Journal of Organizational Culture, Communications \& Conflict, 20(1), 68-77.

Lowe, K. B., \& Gardener, W. L. (2000). Ten years of the leadership quarterly: Contributions and challenges for the future. Leadership Quarterly, 11(4), 459-514. https://doi.org/10.1016/S1048-9843(00)00059-X

Lowe, K. B., Kroeck, G., \& Sivasubramaniam, N. (1996). Effectiveness correlates of transformational and transactional leadership: A meta-analytic review. Leadership Quarterly, 1, 385-426. https://doi.org/10.1016/S1048-9843(96)90027-2

Maslow, A. H. (1954). Motivation and personality. Harper \& Row, New York.

Mayer, D. M., Kuenzi, M., Greenbaum, R., Bardes, M., \& Salvador, R. B. (2009). How low does ethical leadership flow? Test of a trickle-down model. Organizational Behavior and Human Decision Processes, 108(1), 1-13. https://doi.org/10.1016/j.obhdp.2008.04.002

Mayer, D., Kuenzi, M., \& Greenbaum, R. (2010). Examining the link between ethical leadership and employee misconduct: The mediating role of ethical climate. Journal of Business Ethics, 95, 7-16. https://doi.org/10.1007/s10551-011-0794-0 
Mayer, R. C., Davis, J. H., \& Schoorman, F. D. (1995). An interactive model of organizational trust. Academy of Management Review, 20, 709-734.

McFall, L. (1987). Integrity. Ethics, 98(1), 5-20. https://doi.org/10.1086/292912

Monga, M. (2016). Integrity and its antecedent: A unified conceptual framework of integrity. Journal of Developing Areas, 50(5), 415-421. https://doi.org/10.1353/jda.2016.0040

Moorman, R. H., Darnold, T. C., Priesemuth, M., \& Dunn, C. P. (2012). Toward the measurement of perceived leader integrity: Introducing a multidimensional approach. Journal of Change Management, 12(4), 383-398. https://doi.org/10.1080/14697017.2012.728746

Neubert, M. J., Carlson, D. S., Kacmar, K. M., Roberts, J. A., \& Chonko, L. B. (2009). The virtuous influence of ethical leadership behavior: Evidence from the field. Journal of Business Ethics, 90(2), 157-170. https://doi.org/10.1007/s10551-009-0037-9

Nkomo, S. (1996). Identities and the complexity of diversity in selected research on work team diversity. In S. E. Jackson, \& M. N. Ruderman (Eds.), Diversity in work teams: Research paradigms for a changing workplace (pp. 247-254). American Psychological Association, Washington, D.C.

Palanski, M., Cullen, K., Gentry, W., \& Nichols, C. (2015). Virtuous leadership: Exploring the effects of leader courage and behavioral integrity on leader performance and image. Journal of Business Ethics, 132(2), 297-310. https://doi.org/10.1007/s10551-014-2317-2

Parry, K. W., \& Proctor-Thomson, S. B. (2002). Perceived integrity of transformational leaders in organizational settings. Journal of Business Ethics, 35, 75-96. https://doi.org/10.1023/A:1013077109223

Podsakoff, P. M., Mackenzie, S. B., Lee, J. Y., \& Podsakoff, N. P. (2003). Common method biases in behavioral research: A critical review of the literature and recommended remedies. Journal of Applied Psychology, 88(5), 879-903. https://doi.org/10.1037/0021-9010.88.5.879

Rawat, P. S., \& Basergekar, P. (2016). Managing workplace diversity: Performance of minority employees. Indian Journal of Industrial Relations, 51(3), 488-501.

Richard, O. C. (2000). Racial diversity, business strategy, and firm performance: A resource-based view. Academy of Management Journal, 43, 164-177. https://doi.org/10.2307/1556374

Sarros, J. C., \& Santora, J. C. (2001). The transformational-Transactional leadership model in practice. Leadership \& Organization Development, 22(7/8), 383-394. https://doi.org/10.1108/01437730110410107

Surie, G., \& Ashley, A. (2008). Integrating pragmatism and ethics in entrepreneurial leadership for sustainable value creation. Journal of Business Ethics, 81(1), 235-246. https://doi.org/10.1007/s10551-007-9491-4

Treviño, L. K., \& Brown, M. E. (2004). Managing to be ethical: Debunking five business ethics myths. Academy of Management Executive, 18(2), 69-81. https://doi.org/10.5465/AME.2004.13837400 
van Gils, S., Van Quaquebeke, N., van Knippenberg, D., van Dijke, M., \& de Cremer, D. (2015). Ethical leadership and follower organizational deviance: The moderating role of follower moral $\begin{array}{llll}\text { attentiveness. The } & \text { Leadership }\end{array}$ https://doi.org/10.1016/j.leaqua.2014.08.005

Zhu, W., He, H., Treviño, L., Chao, M., \& Wang, W. (2015). Ethical leadership and follower voice and performance: The role of follower identifications and entity morality beliefs. The Leadership Quarterly, 26, 702-718. https://doi.org/10.1016/j.leaqua.2015.01.004

Zhu, W., Treviño, L. K., \& Zheng, X. (2016). Ethical leaders and their followers: The transmission of moral identity and moral attentiveness. Business Ethics Quarterly, 26(1), 95-115. https://doi.org/10.1017/beq.2016.11 